\title{
Key factors in achieving increased tobacco taxation: Experience from the island of Saint Helena
}

\author{
Angela Jackson-Morris' ${ }^{1}$ Laura Rossouw ${ }^{2,3}$, Micheal K. Boachie ${ }^{2}$
}

\begin{abstract}
Concerted efforts by government officials and technical assistance from the World Health Organization (WHO) Framework Convention on Tobacco Control (FCTC) Secretariat Knowledge Hub on Tobacco Taxation and Illicit Trade, resulted in an increase in tobacco taxation in Saint Helena during 2019. This formed part of a broader package of Tobacco Control measures to reduce the burden of noncommunicable diseases (NCD) on the island. We elaborate on key contextual and contributing factors that resulted in positive policy change in a relatively short period of time. These included political support for a strategic approach to address prevalent NCD in the context of an ageing population, high overseas health care costs and Overseas Development Aid dependency. Previous experience of impact from sugar-sweetened beverage taxation when combined with wider system measures, and the similar accompaniment of the tobacco taxation proposals with wider measures, encouraged policymakers to use tobacco taxation to curb cigarette consumption. These factors created readiness, and tailored technical assistance from an international, donor-funded partner and specifically modelling to provide evidence-based predictions of impact augmented confidence of policy benefit and enabled passage. This experience may serve as a point of reference for other countries that wish to implement similar policy changes.
\end{abstract}

\section{AFFILIATION \\ 1 Health Directorate, Saint Helena Government, Jamestown, Saint Helena \\ 2 WHO FCTC Secretariat Knowledge Hub on Taxation, South Africa National Department of Health, Cape Town, South Africa \\ 3 School of Economics and Finance, University of the Witwatersrand, \\ Johannesburg, South Africa \\ CORRESPONDENCE TO \\ Angela Jackson-Morris. Health Directorate, Saint Helena Government, Jamestown, Saint Helena. E-mail: ajacksonmorris@ gmail. com \\ KEYWORDS \\ tobacco, health policy, non- communicable diseases, taxation, FCTC}

Received: 26 February 2020

Revised: 17 April 2020

Accepted: 14 May 2020

\section{COMMENTARY}

Article 6 of the World Health Organization's (WHO) Framework Convention on Tobacco Control (FCTC) commits Parties to use tax and price policies to control tobacco consumption ${ }^{1}$. The WHO FCTC is the first global health treaty, guiding its Parties to a coordinated response to curbing the global tobacco epidemic. Evidence on tax and price policies shows that they are the most effective means of influencing the demand for tobacco products ${ }^{2}$. Consequently, implementation of FCTC Article 6 is an important element of a country's tobacco control strategy.

Saint Helena is a self-governing UK Overseas Territory (UKOT), with historical and political ties to the $\mathrm{UK}^{3}$. The island is geographically within the WHO AFRO region, and although officially categorised as an upper-middle-income country, it is not economically self-sufficient, and depends substantially on Overseas Development $\mathrm{Aid}^{4}$.

Tobacco-related non-communicable diseases (NCDs), such as cancer, cardiovascular disease, chronic lung disease, and diabetes, account for a large share of ill-health and mortality on the island. Specifically, one fifth of the population is diabetic, and half of adults have been assessed as hypertensive ${ }^{5}$. NCD treatment accounts for a large proportion of the health budget. Tobacco use is high, with $24.2 \%$ ( $\geq 15$ years old) smoking and very 
high rates among young men (50\%) and women $(46 \%)$ in the cohort aged 20-29 years ${ }^{6}$. Needs assessment in 2018 identified that smoking was seen to be accepted widely in the community at all social occasions and places, and relatively affordable. In addition, Saint Helena has an ageing population structure resembling more industrialised countries, and population projections estimate that this ratio will increase $\mathrm{e}^{4}$. This has macroeconomic implications such as fewer economically active citizens and increased healthcare expenditure ${ }^{7,8}$. These were some of the important contextual considerations for strengthening tobacco control measures, particularly tobacco taxation.

To provide a reference point for countries wishing to make a policy change, this policy case study examines the 2019 increase in tobacco excise tax in Saint Helena that resulted from a collaborative effort by the Saint Helena government and the WHO FCTC Secretariat Knowledge Hub (WHO KH) on Tobacco taxation and illicit trade at the University of Cape Town, South Africa.

\section{Tobacco taxation policy as part of a wider framework of tobacco control measures}

The tobacco taxation proposals were designed as part of a broader strategic programme to reduce the prevalence of NCDs and the associated economic burden. By 2017 there was strong political support to re-orientate the health system and increase collaboration across government departments to develop stronger NCD prevention. Plans to develop chronic disease management were outlined, and in early 2018 a Health Promotion Strategic Framework (HPSF) was developed. This focused on two leading preventable risk factors - smoking and obesity, adopting a 'whole system' approach to address environmental influences and enhance health literacy ${ }^{5}$.

Tobacco taxation was among the tobacco control strategies, and a range of important developments had started to happen and to show positive impact in the previous year. A 'Smoke-Free Government' (SFG) policy was introduced, creating fully smokefree indoor and outdoor public spaces across a large number of government-owned employment and community sites, and ending the practice of sanctioned 'smoke breaks' for all government staff (about $25 \%$ of all adults on the island). At the same time, the island's first smoking cessation support service commenced, providing advice, support and free courses of nicotine replacement therapy, and community social marketing promoted the newly available support to help smokers quit. Concurrently, legislative proposals were being developed to meet the key provisions of FCTC, particularly to strengthen policy on packaging, advertising, and protection from secondhand smoke exposure ${ }^{9}$.

The development of the tobacco taxation proposals took place in this context of strategic focus, high profile policies and service development, and public information and discussion in the media and community about smoking. The political debates about the tax increases reflected themes reported in other countries ${ }^{10}$, particularly the role of price in deterring youth from starting to smoke and whether the tax would unfairly penalise smokers on low incomes. Discussions indicated that increasing excise taxes and thereby the price of tobacco as a standalone measure may have been politically unpalatable; whereas the case to increase taxes was reported to have been strengthened by being considered against a backdrop of increased quit support, community quit awareness, and wider policies to reduce and restrict smoking.

The view that the taxation proposals were stronger by being accompanied by wider measures was additionally influenced by a parallel area of NCD prevention: reducing sugar-sweetened beverages (SSBs) consumption. In 2018, the government's health directorate worked with large importers and retailers of soft drinks to improve supply of sugar-free drinks on the island and undertook social marketing to encourage a shift away from SSBs. This supply/ demand initiative was accompanied by increased taxes on sugary drinks. SSB consumption declined and water intake increased ${ }^{11}$. The combination of the commercial and community measures to support the tax increase was considered to have been key in achieving impact and was cited by policymakers as a further reason to view the tobacco excise proposals positively, as they were supported by wider actions.

\section{Academic-government collaboration to achieve population tobacco control policy}

The WHO KH is housed in the Research Unit on the 
Economics of Excisable Products (REEP), University of Cape Town, South Africa. The KH supports Parties to the FCTC by facilitating training, capacity building, technical assistance and knowledge dissemination in the areas of taxation (Article 6) and illicit trade (Article 15) and is funded by international donor foundations, including Cancer Research UK.

There are seven WHO FCTC Knowledge Hubs globally, each focused on various articles of the FCTC (https://untobaccocontrol.org/intro/). While they mimic elements of civil society organizations, they do not necessarily participate in advocacy activities. The WHO KH provides fact sheets to simplify and make more accessible tobacco taxation and illicit trade related topics. Most KHs also work with country-level policymakers ${ }^{12}$.

There are documented reports of academic institutions contributing to the implementation of tobacco control policies in South Africa ${ }^{13,14}$. The capacity of academia in this regard has been largely to provide research support to civil society organisations or provide evidence for advocacy to policymakers ${ }^{13}$.

The credibility of the WHO KH, with an established reputation in tobacco taxation, made it an attractive partner to support the Government of Saint Helena's desire to develop effective tobacco taxation. This was greatly significant in augmenting policymakers' confidence that the recommendations were robust and evidence-based. Expertise on specific economic policy areas is not generally available within governments, particularly smaller governments, and so expert, impartial tobaccospecific economics input was seen to add value and complement the government's strong understanding of the local economy.

\section{The role of modelling}

The TETSiM model is a quantitative, tax simulation model designed by researchers at REEP ${ }^{1}$. It is a partial equilibrium model used to illustrate what could happen to the average retail price, consumption, and excise tax revenue if excise tax on tobacco products increases, and has been shown to be an accurate predictor of these outcomes ${ }^{15}$.

The WHO KH has developed and applied the TETSiM model for many countries. In this case, the model was Saint Helena specific, populated with credible local data from government departments. The model reflected the current tobacco tax structure and level of cigarette consumption. Reflecting the current levels of cigarette consumption in Saint Helena, the model takes into account the consumption of the top three most consumed cigarette brands in the country (L\&M, Benson \& Hedges, and Brand-555), and allows for differing consumer responses to price changes. Given the uniform, specific tax structure, the model was used to calculate various politically viable tobacco excise tax changes and their probable impact on government revenue, and cigarette consumption and deaths to be avoided. The results from the TETSiM model were valued as evidencebased, reliable, and perhaps most importantly, locally tailored - a crucial consideration for policymakers wishing to ensure their circumstances are reflected.

The primary value of the model was to confirm tangibly, based on data, what could be expected to occur to tobacco consumption, and to forecast what would happen to revenue. While the health impetus was a key driver, it was important to identify a specific level for the taxation increase and show the likely revenue impacts because of this. In the wider Saint Helena economic and political context, whereby increasing government revenue is a priority, it was of major importance to be able to show a level of increase that would both decrease consumption as well as guarantee and even increase government revenue in the short-to-medium term. A policy proposal that would decrease consumption and reduce tobacco excise revenue may have been unlikely to achieve the broad political support required for the policy to pass. Modelling has the added benefit of creating a clear roadmap of the planned policy change, effectively easing some of the uncertainty for manufacturers and sellers of cigarettes and tobacco products.

Several models were initially presented and discussed by the Public Health Committee. It was determined that the second modelled option would be optimal for the island, enabling an important reduction in consumption, while moderating the level of tax increase, to be effective while acceptable to the public. Taxation proposals generally are considered by the island's Economic Committee and so the proposal first was considered by this 
body as a tax rather than a health measure and was not supported. As a matter of wider population significance, the case was made that the proposal should receive consideration by the full Council, with opportunity for Members to identify questions and concerns. Following presentation and debate, the proposal was taken to the island's highest policy body, and after this session members were able to further scrutinise the proposal about its role and potential impacts for the community, with support from the government health directorate. The proposal was presented and discussed at the Executive Committee and was unanimously passed in August 2019 and implemented from October 2019.

The final successful policy proposal, presented in Table 1, had a $13.98 \%$ increase in excise tax in 2019 , followed by an annual inflationary tax increase of $3.8 \%$, plus an additional $1 \%$.

The model predicts that (given a set of assumptions) by 2023 , the government will collect $£ 1.136$ million (in 2018 prices) annually as excise revenue. This is an increase from the $£ 0.931$ million annual collection. Cigarette consumption will decline substantially, resulting in public health benefits (Table 1 ). While we observe approximately $11 \%$ reduction in cigarette consumption, the reduction in smoking prevalence is only half of this at $5.6 \%$ (or 1 percentage point). This is based on the assumption that reduction in consumption is partially driven by smokers quitting but also smokers just decreasing their daily consumption. The proposed policy will result in the avoidance of smoking-related deaths. These are projected relative to the number of births in Saint Helena for context. Over the period of assessment, annual lives saved are equivalent to between $20 \%$ and $30 \%$ of the number of births in 2018.

\section{CONCLUSION}

We identified several factors that contributed to the successful passage of tobacco taxation measures in Saint Helena. The uniform excise tax structure in Saint Helena was conducive to increasing government revenue and reducing smoking prevalence. Taxation was part of a wider framework of mutually-reinforcing strategies and this added strength and impetus to the case. Emphasis must be placed upon a critical factor that enabled these facilitating circumstances to be translated into an effective, implementable policy in practice - this was the collaboration with academic tobacco control economists, which added specific expertise otherwise unavailable, yet was tailored to local needs. Such collaborations may be possible where a government has an existing local academic partner and/or can fund work to support policy development. International support where this is not the case is of major importance. Funders rightly prioritise funding for low- and middle-income countries, however, official income group status alone may exclude territories with substantial need and poor capacity to meet these.

Table 1. TETSiM modelling results after a proposed increase in excise tax

\begin{tabular}{|c|c|c|c|c|c|c|c|}
\hline & \multicolumn{7}{|c|}{ Absolute annual values } \\
\hline & $2018^{*}$ & 2019 & 2020 & 2021 & 2022 & 2023 & $\begin{array}{l}\text { Five } \\
\text { year } \\
\text { change }\end{array}$ \\
\hline Total excise revenue (in units of $1000 \mathrm{f}$ ) & 931 & 1018 & 1046 & 1075 & 1105 & 1136 & 205 \\
\hline Excise tax burden (\%) & 63.6 & 65.4 & 65.4 & 65.3 & 65.3 & 65.2 & 1.7 \\
\hline Excise tax per pack (€) & 3.7 & 4.2 & 4.5 & 4.7 & 4.9 & 5.1 & 1.4 \\
\hline Percentage increase in tax & baseline & 13.98 & 4.8 & 4.8 & 4.8 & 4.8 & \\
\hline Retail price per pack $(€)^{\mathrm{b}}$ & 5.9 & 6.5 & 6.8 & 7.1 & 7.5 & 7.9 & 2.0 \\
\hline Cigarette consumption (packs of 20 sticks) & 249924 & 239690 & 235072 & 230493 & 226062 & 221719 & -28204 \\
\hline Smoking prevalence $(\%)$ (people $\geq 15$ years old) & 24 & 24 & 23 & 23 & 23 & 23 & -1 \\
\hline $\begin{array}{l}\text { Percentage of premature deaths avoided (number } \\
\text { of people as a percentage of } 2018 \text { births) }\end{array}$ & - & 38 & 27 & 27 & 23 & 23 & \\
\hline
\end{tabular}

*Baseline year. a All in Saint Helena pounds (£). b Amounts are in 2018 prices. 


\section{REFERENCES}

1. World Health Organization. The WHO Framework Convention on Tobacco Control: an overview. Geneva, Switzerland: World Health Organization; 2003. https:// www.who.int/fctc/about/WHO_FCTG_summary_ January2015.pdf?ua=1. Accessed April 17, 2020.

2. U.S. National Cancer Institute, World Health Organization. Monograph 21: The Economics of Tobacco and Tobacco Control. National Cancer Institute Tobacco Control. In: NIH Publication No 16-CA-8029A. Bethesda, MD: U.S. Department of Health and Human Services, National Institutes of Health, National Cancer Institute, National Cancer Institute; 2016. https://cancercontrol.cancer. gov/brp/tcrb/monographs/21/docs/m21_exec_sum.pdf. Accessed April 17, 2020.

3. Health and Healthcare in the British Overseas Territories: Regional and UK Government Support. https://assets. publishing.service.gov.uk/government/uploads/system/ uploads/attachment_data/file/216560/dh_134545.pdf. Published 2010. Accessed April 17, 2020.

4. Government of Saint Helena. Estimates of Revenue, Expenditure and Capital Expenditure 2019/20 - 202021. https://www.sainthelena.gov.sh/wp-content/ uploads/2019/03/SHG-Budget-Book-2019-20.pdf. Accessed April 17, 2020.

5. Government of Saint Helena. Strategic Framework for Health Promotion on St Helena (2018-2019) 238. http://www.sainthelena.gov.sh/wp239/content/ uploads/2018/05/Strategic-Framework-for-HealthPromotion-in-St-Helena-Final.pdf. Accessed April 17, 2020.

6. Government of Saint Helena, Statistics Office. St Helena 2016 Population \& Housing Census: Summary report. http://www.sainthelena.gov.sh/wp-content/ uploads/2016/06/Census-2016-Summary-Report.pdf. Published 2016. Accessed April 17, 2020.

7. Bloom DE, Chatterji S, Kowal P, Lloyd-Sherlock P, McKee M, Rechel B, Rosenberg L, Smith JP. Macroeconomic implications of population ageing and selected policy responses. Lancet. 2015;385(9968):649-657. doi:10.1016/s0140-6736(14)61464-1

8. Divo MJ, Martinez CH, Mannino DM. Ageing and the epidemiology of multimorbidity. Eur Respiratory Soc. 2014;44(4):1055-1068. doi:10.1183/09031936.00059814

9. Jackson-Morris A. The contribution of a 'whole of government' smoke-free policy on the island of St Helena. Glob Health Action. 2019;12(1):1681756. doi:10.1080/16549716.2019.1681756

10. Warner KE. The economics of tobacco: myths and realities. Tob Control. 2000;9(1):78-89. doi:10.1136/tc.9.1.78

11. Government of Saint Helena. Economic Development Committee Meeting - Thursday 25 April, 2019. http:// www.sainthelena.gov.sh/economic-developmentcommittee-meeting-thursday-25-april-2019/. Published May 3, 2019. Accessed May 14, 2020.
12. Mehrotra R, Grover S, Chandra A. Role of world health organization framework convention on tobacco control global knowledge hub on smokeless tobacco. Indian J Med Res. 2018;148(1):7-13. doi:10.4103/ijmr.ijmr_2036_17

13. Drope JM. The politics of smoke-free policies in developing countries: Lessons from Africa. GVD Prevention and Control. 2010;5(3):65-73. doi:10.1016/j.cvdpc.2010.07.001

14. Van Walbeek C. Tobacco control in South Africa in the 1990s: a mix of advocacy, academic research and policy. South African Journal of Economic History. 2004;19(12):100-131. doi:10.1080/10113430409511172

15. Van Walbeek C. A simulation model to predict the fiscal and public health impact of a change in cigarette excise taxes. Tob Control. 2010;19(1):31-36. doi:10.1136/tc.2008.028779

\section{ACKNOWLEDGEMENTS}

Our thanks to Members of the Public Health Committee of the Saint Helena Government (SHG), who championed the tobacco taxation proposals, and to the SHG Finance and Statistics teams who provided data and support to the proposals.

\section{CONFLICTS OF INTEREST}

The authors have completed and submitted the ICMJE Form for Disclosure of Potential Conflicts of Interest and none was reported.

\section{FUNDING}

The WHO FCTC Knowledge Hub on Tobacco Taxation and Illicit Trade receives funding from Cancer Research UK (Grant number: C62640/ A24723)

\section{PROVENANCE AND PEER REVIEW}

Not commissioned; externally peer reviewed. 